\title{
Оцінка функціональної підготовленості підлітків 11-12 років за показниками аеробної й анаеробної продуктивності
}

\author{
УДК [612:796.015.572/.574]-053.66 \\ Ю. М. Фурман, О. Ю. Брезденюк, В. М. Мірошніченко
}

Вінницький державний педагогічний університет імені Михайла Коцюбинського, Вінниця, Україна

Резюме. Мета. Встановити стандарти оцінки функціональної підготовленості підлітків 11-12 років. Методи. Педагогічний експеримент із використанням велоергометрії, пульсометрії, сфігмоманометрії, хронометрії; методи математичної статистики. Досліджено показники аеробної й анаеробної продуктивності 1417 підлітків 11-12 років. Створено стандарти функціональної підготовленості на основі середніх арифметичних $(\overline{\mathrm{X}})$ та середніх квадратичних відхилень $(\sigma)$ показників максимального споживання кисню $\left(\mathrm{VO}_{2} \max \right)$ і максимальної кількості зовнішньої механічної роботи за 10 с (ВАнТ 10 ), 30 с (ВАн (ВТ $\left._{30}\right)$, за 1 хв (МКЗР). Результати. Розроблено критерії функціональної підготовленості за рівнями: «середній»; «вище середнього»; «нижче середнього»; «високий»; «низький»; «дуже високий»; «дуже низький». За середній рівень взяли діапазон похибки середнього квадратичного відхилення від середнього арифметичного варіаційного ряду значень дослідженого нами контингенту $(\overline{\mathrm{X}} \pm \sigma)$. На основі даних, отриманих експериментальним шляхом розробили критерії оцінки аеробної і анаеробної продуктивності дівчат і хлопців віком 11-12 років. Висновки. Стандарти функціональної підготовленості слід розробляти за середнім значенням показника, отриманого в результаті обстеження великої кількості осіб однорідного контингенту.

Розроблені стандарти охоплюють увесь спектр функціональної підготовленості підлітків 11-12 років.

Ключові слова: аеробна продуктивність, анаеробна продуктивність, стандарти, дівчата, хлопці.

Estimating functional fitness of teenagers aged 11-12 years by indices of aerobic and anaerobic productivity

Y. M. Furman, O. Y. Brezdeniuk, V. M. Miroshnichenko

Mykhailo Kotsyubynsky Vinnytsia State Pedagogical University, Vinnytsia, Ukraine

Abstract. Objective. To establish standards for the assessment of functional fitness of teenagers aged 11-12 years. Methods. Pedagogical experiment using veloergometry, pulsometry, sphygmomanometry, timekeeping; methods of mathematical statistics. Indices of aerobic and anaerobic performance of 1417 adolescents aged 11-12 years were examined. The standards of functional fitness based on the arithmetic mean $(\bar{X})$ and standard deviations $(\sigma)$ of the indices of maximal oxygen consumption $\left(\mathrm{NO}_{2}\right.$ max) and maximum amount of external mechanical work in $10 \mathrm{~s}\left(\mathrm{WAnT}_{10}\right), 30 \mathrm{~s}$ $\left(\mathrm{WAnT}_{30}\right)$, and 1 min (MAEW) were formed. Results. The criteria of functional fitness were developed according to the levels: «average»; «above average»; «below average»; «high»; «low»; «very high»; «very low». The range of error of the standard deviation from the arithmetic mean of the variation series of values of the examined contingent was taken as a mean level $(\bar{X} \pm \sigma)$. Based on the experimental data, criteria were developed to evaluate the aerobic and anaerobic performance of girls and boys aged 11-12 years. Conclusions. Functional fitness standards should be developed on the basis of the average of the index obtained as a result of examining a large number of persons of a uniform contingent. Developed standards cover the whole spectrum of functional fitness of teenagers aged 11-12 years.

Keywords: aerobic productivity, anaerobic productivity, standards, girls, boys. 
Постановка проблеми. Чимало сучасних наукових публікацій з фрізіології рухової активності свідчать про недостатній рівень функціональної підготовленості населення України [2, 3, 9].

Як відомо, чітко визначених рекомендацій щодо оцінки рівня фрункціональної підготовленості людини не існує. Г. Л. Апанасенко [1], Я. П. Пярнат [8], Ю. М. Фурман [11] пропонують використовувати з цією метою показник потужності аеробних процесів енергозабезпечення $\left(\mathrm{NO}_{2} \max \right)$ тому, що у загальній сумі енергопотенціалу організму аеробне енергоутворення значно переважає анаеробне [12, 13]. Значну роль у формуванні енергетичного потенціалу відіграють і анаеробні процеси метаболізму [7, 11, 14]. Тому, щоб отримати повну інфрормацію про функціональну підготовленість, слід враховувати як аеробну, так і анаербну складову.

Єдиних критеріїв оцінки аеробних можливостей людини не існує. Опубліковані різними авторами дані дещо відрізняються. Причому більшість оціночних критеріїв цього показника стосуються осіб віком старших 20 років. Винятком $\epsilon$ критерії оцінки Я. П. Пярната [8]. Дані критерії охоплюють широкий віковий діапазон (від 10 до 50 років), але не враховують особливості регіону. Крім цього, критерії з часом повинні періодично оновлюватися.

Так, Г. Л. Апанасенко [1] пропонує оцінювати аеробну продуктивність за критерієм «безпечний рівень здоров'я», який визначається за відносною величиною $\mathrm{V}_{2} \max$. Для чоловіків даний рівень становить 42,0 мл $\cdot \mathrm{xB}^{-1} \cdot \mathrm{K}^{-1}$, а для жінок 35,0 мл $\cdot \mathrm{xB}^{-1} \cdot \mathrm{kr}^{-1}$. Сучасні дослідження свідчать про перевищення середньогрупових значень відносного показника $\dot{V}_{2} \max$ у дівчат 17-19 років за критерієм «безпечний рівень здоров'я» $[3,18]$. У чоловіків спостерігається протилежна картина - середньогрупові значення $\dot{\mathrm{V}}_{2} \max$ знаходяться нижче критерія «безпечний рівень здоров'я» $[2,9,15]$. Тому цей критерій потребує уточнення на відповідність сучасному стану здоров'я населення України.

Для оцінки аеробних можливостей організму використовують модифрікований тест К. Купера [6]. Цей тест полягає у виконанні 12-хвилинного бігу. Враховується дистанція, яку долає досліджуваний за цей час, і чСС за перші 30 с на початку 2-ї, 3-ї та 4-ї хвилин періоду відновлення. Недоліком даної методики $€$ відсутність критеріїв оцінки, які враховують вік людини та не враховують відмінності регіону.

Для визначення анаеробної продуктивності організму існують тести ВАнТ ${ }_{10}$, ВАнТ $_{30}$, МКЗР
[17]. Оціночних критеріїв анаеробної продуктивності в наукових джерелах ми не зустрічали. Тому оцінювали анаеробну продуктивність шляхом порівняння середніх значень показників різних досліджуваних груп.

Відмінність середніх значень показників аеробної і анаеробної продуктивності організму осіб, які мешкають у різних регіонах України, встановили О. А. Дуло та Ю. М. Фурман [3]. Відтак постає необхідність розробити критерії, які враховують вищезгадані чинники.

У попередніх роботах ми оприлюднили розроблені нами критерії аеробної і анаеробної продуктивності осіб 17-19 років [16], а також 2022 років [10] із урахуванням усіх вищезгаданих чинників, у тому числі й регіональних. Наступним етапом дослідження $€$ розробка критеріїв для вікової групи підлітків 11-12 років.

Мета дослідження - встановлення стандартів оцінки функціональної підготовленості підлітків 11-12 років.

Методи і організація дослідження. У дослідженні взяли участь 685 дівчат та 732 хлопців віком 11-12 років, які навчалися у середніх загальноосвітніх школах Вінниці та Вінницької області.

У досліджуваних вивчали показники функціональної підготовленості. Потужність аеробних процесів енергозабезпечення визначали за величиною максимального споживання кисню ( $\left.\mathrm{O}_{2} \mathrm{max}\right)$, яка розраховувалася за значенням велоергометричного тесту PWC PI0 $_{17}$ [5].

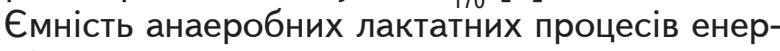
гозабезпечення визначали за показником максимальної кількості зовнішньої механічної роботи за 1 хв (МКЗР), використовуючи методику A. Shögy, G. Cherebetin [19]. Показники потужності анаеробних алактатних процесів енергозабезпечення визначали за Вінгейтським анаеробним тестом ВАнТ 10 , а потужності анаеробних лактатних процесів енергозабезпечення - за Вінгейтським анаеробним тестом $\mathrm{BAнT}_{30}[11,17]$.

Статистичну обробку даних, отриманих під час дослідження, здійснювали за допомогою методів математичної статистики. Визначали такі показники, як середнє арифрметичне $(\bar{X})$ та середнє квадратичне відхилення $(\sigma)$ [4]. На основі отриманих даних розробляли критерії оцінки аеробної й анаеробної продуктивності підлітків 11-12 років.

Результати дослідження та їх обговорення. Для розробки стандартів функціональної підготовленості ми використали авторську методику, яка опублікована у наших попередніх дослідженнях, спрямованих на встановлення стандартів фрізичної та фрункціональної підготов- 
ТАБЛИЦЯ 1 - Стандарти функціональної підготовленості дівчат 11-12 років за показниками $\mathrm{V}_{2} \max$, BАнТ $_{10}$, BАнТ $_{30}$, MK3P $(n=685)$

\begin{tabular}{|c|c|c|c|c|c|c|c|c|c|}
\hline \multirow[b]{2}{*}{ Сигма } & \multirow{2}{*}{$\begin{array}{c}\text { Рівень } \\
\text { функціо- } \\
\text { нальної } \\
\text { підготов- } \\
\text { леності }\end{array}$} & \multicolumn{2}{|c|}{ Аеробна продуктивність } & \multicolumn{6}{|c|}{ Анаеробна продуктивність } \\
\hline & & $\begin{array}{l}\dot{\mathrm{V}} \mathrm{O}_{2} \max \\
\mathrm{M} \mathbf{X B}^{-1}\end{array}$ & $\begin{array}{l}\dot{\mathrm{V}} \mathrm{O}_{2} \max \\
\mathrm{M} \cdot \mathrm{XB}^{-1} \cdot \mathrm{K} \Gamma^{-1}\end{array}$ & $\begin{array}{l}\mathrm{BAHT}_{10} \\
\kappa \Gamma \mathrm{M} \cdot \mathrm{XB}^{-1}\end{array}$ & $\begin{array}{c}\text { BAHT }_{10}, \\
\kappa \Gamma M \cdot \mathbf{X B}^{-1} \cdot \mathrm{K}^{-1}\end{array}$ & $\begin{array}{l}\text { BAнT }_{30} \\
\mathrm{~K} Г \mathrm{M} \cdot \mathrm{XB}^{-1}\end{array}$ & $\begin{array}{c}\text { ВАнТ }_{30}, \\
\kappa \Gamma M^{*} \cdot \mathbf{X B}^{-1} \cdot \mathrm{KT}^{-1}\end{array}$ & $\begin{array}{c}\text { МКЗР, } \\
\text { кГм'х } \mathbf{X B}^{-1}\end{array}$ & 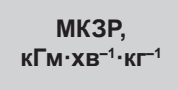 \\
\hline$>2,0 \sigma$ & $\begin{array}{l}\text { Дуже } \\
\text { високий }\end{array}$ & $>2349,1$ & $>58,7$ & $>1136,6$ & $>27,8$ & $>1139,7$ & $>27,5$ & $>1293,3$ & $>32,4$ \\
\hline $1,1-2,0 \sigma$ & Високий & $2151,1-2349,1$ & $53,7-58,7$ & $1001,3-1136,6$ & $24,7-27,8$ & $989,4-1139,7$ & $24,2-27,5$ & $1173,2-1293,3$ & $29,4-32,4$ \\
\hline $0,6-1,0 \sigma$ & $\begin{array}{l}\text { Вище се- } \\
\text { реднього }\end{array}$ & $\begin{array}{l}2041,1- \\
-2129,1\end{array}$ & $51,0-53,2$ & $925,9-986,2$ & $22,9-24,3$ & $905,9-972,7$ & $22,3-23,8$ & $1106,9-1160,0$ & $27,7-29,0$ \\
\hline $\begin{array}{l}+0,5 \sigma- \\
-( \pm 0,5 \sigma)- \\
--0,5 \sigma\end{array}$ & Середній & $\begin{array}{c}2019,1- \\
-(1909,1 \pm \\
\pm 110,0)- \\
-1799,1\end{array}$ & $\begin{array}{c}50,4- \\
(47,7 \pm \\
\pm 2,75)- \\
-44,9\end{array}$ & $\begin{array}{c}910,4- \\
-(835,4 \pm \\
\pm 75,4)- \\
-760,0\end{array}$ & $\begin{array}{c}22,5- \\
-(20,8 \pm \\
\pm 1,75)- \\
-19,05\end{array}$ & $\begin{array}{c}889,2- \\
-(805,7 \pm \\
\pm 83,5)- \\
-722,2\end{array}$ & $\begin{array}{c}-21,9(20,1 \pm \\
\pm 1,86)- \\
-18,2\end{array}$ & $\begin{array}{c}1093,2- \\
-(1026,5 \pm \\
\pm 66,7)- \\
-959,8\end{array}$ & $\begin{array}{l}-27,4(25,7 \pm \\
\pm 1,67)-24,0\end{array}$ \\
\hline$-0,6--1,0 \sigma$ & $\begin{array}{l}\text { Нижче се- } \\
\text { реднього }\end{array}$ & $\begin{array}{c}1777,1- \\
-1689,1 \\
\end{array}$ & $44,4-42,2$ & $\begin{array}{l}744,9- \\
-684,6 \\
\end{array}$ & $18,7-17,3$ & $705,5-638,7$ & $17,9-16,4$ & $946,1-898,1$ & $23,7-22,4$ \\
\hline$-1,1--2,0 \sigma$ & Низький & $\begin{array}{c}1667,1- \\
-1549,1 \\
\end{array}$ & $41,7-36,7$ & $699,5-533,8$ & $16,9-13,8$ & $622,0-471,7$ & $16,0-12,7$ & $879,8-759,7$ & $22,0-19,0$ \\
\hline$<-2,0 \sigma$ & $\begin{array}{l}\text { Дуже } \\
\text { низький }\end{array}$ & $<1469,1$ & $<36,7$ & $<533,8$ & $<13,8$ & $<471,7$ & $<12,7$ & $<759,7$ & $<19,0$ \\
\hline
\end{tabular}

Примітка. $\square$ - середній рівень функціональної підготовленості.

леності чоловіків та жінок 17-19 та 20-22 років $[10,16]$. Відповідно до даної методики середній рівень ознаки відповідає діапазону $\pm 0,5 \sigma$. Рівень «вище середнього» або «нижче середнього» рекомендуємо визначати в межах діапазону 0,6 $\sigma-$ $1 \sigma$ або $(-0,6 \sigma)-(-1 \sigma)$ відповідно, а «високий» i «низький» рівень знаходити в межах діапазону $1,1 \sigma-2 \sigma$ або $(-1,1 \sigma)-(-2 \sigma)$. «Дуже високий» рівень слід знаходити в межах $>2,0 \sigma$, а «дуже низький» - в межах $<-2,0 \sigma$.

У таблицях 1 і 2 представлені розроблені нами стандарти фуннцціональної підготовленості підлітків 11-12 років.
Отримані нами дані істотно відрізняються від існуючих критеріїв. Так, «середній» рівень аеробної продуктивності дівчат 11-12 років (див. табл. 1) знаходиться вище встановленого Г. Л. Апанасенком критерія «безпечний рівень здоров'я» [1]. За критеріями Я. П. Пярната «відмінний» рівень аеробної продуктивності досліджуваного контингенту відповідає значенням $>47$ мл $\mathrm{XB}^{-1} \cdot \mathrm{Kг}^{-1}[8]$. Однак, за нашими даними (див. табл. 1), величина $47 \mathrm{мл} \cdot \mathrm{XB}^{-1} \cdot \mathrm{k}^{-1}$ відповідає лише «середньому» рівню.

Дані таблиці 2 вказують на те, що у хлопців 11-12 років «середній» рівень аеробної продуктив-

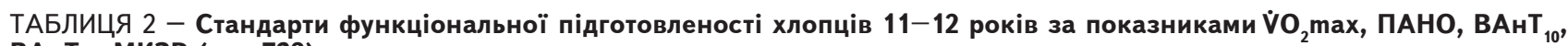
ВАнТ $_{30}$, МКЗР $(n=732)$

\begin{tabular}{|c|c|c|c|c|c|c|c|c|c|}
\hline \multirow[b]{2}{*}{ Сигма } & \multirow{2}{*}{$\begin{array}{c}\text { Рівень } \\
\text { функціо- } \\
\text { нальної } \\
\text { підготов- } \\
\text { леності }\end{array}$} & \multicolumn{2}{|c|}{ Аеробна продуктивність } & \multicolumn{6}{|c|}{ Анаеробна продуктивність } \\
\hline & & 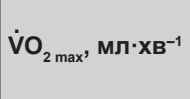 & 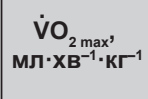 & $\begin{array}{l}\mathrm{BAHT}_{10}, \\
\mathrm{KГM} \cdot \mathbf{X B}^{-1}\end{array}$ & $\begin{array}{c}\mathrm{BAHT}_{10} \\
\mathrm{~K} \mathrm{M}^{\prime} \cdot \mathbf{X B}^{-1} \cdot \mathrm{Kr}^{-1}\end{array}$ & $\begin{array}{l}\mathrm{BAHT}_{30}, \\
\mathrm{~K} \Gamma \mathrm{M} \cdot \mathrm{XB}^{-1}\end{array}$ & 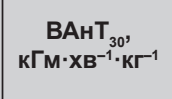 & МКЗР, кГм'хв & $\begin{array}{c}\text { МКЗР, } \\
\text { КГM } \times \mathrm{XB}^{-1} \cdot \mathrm{Kr}^{-1}\end{array}$ \\
\hline$>2,0 \sigma$ & $\begin{array}{l}\text { Дуже } \\
\text { високий }\end{array}$ & $>2392,5$ & $>57,0$ & $>1181,3$ & $>28,1$ & $>1204,4$ & $>28,7$ & $>1457,4$ & $>34,7$ \\
\hline $1,1-2,0 \sigma$ & Високий & $2227,8-2392,5$ & $53,0-57,0$ & $1051,2-1181,3$ & $25,0-28,1$ & $1058,0-1204,4$ & $25,3-28,7$ & $1312,5-1457,4$ & $31,2-34,7$ \\
\hline $0,6-1,0 \sigma$ & \begin{tabular}{|l|} 
Вище \\
середнього
\end{tabular} & $2136,3-2209,5$ & $50,9-52,6$ & $979,0-1036,7$ & $23,3-24,6$ & $977,0-1042,0$ & $23,3-24,9$ & $1232,0-1296,4$ & $29,3-30,8$ \\
\hline $\begin{array}{l}+0,5 \sigma- \\
-( \pm 0,5 \sigma)- \\
--0,5 \sigma\end{array}$ & Середній & $\begin{array}{c}2118,0- \\
-(2026,5 \pm \\
\pm 91,5)- \\
-1935,0 \\
\end{array}$ & $\begin{array}{c}50,5- \\
-(48,3 \pm \\
\pm 2,18)- \\
-46,1\end{array}$ & $\begin{array}{c}964,4- \\
(892,1 \pm \\
\pm 72,3)- \\
-819,8 \\
\end{array}$ & $\begin{array}{c}22,9- \\
(21,2 \pm \\
\pm 1,72)- \\
-19,5\end{array}$ & $\begin{array}{c}960,8- \\
(879,6 \pm \\
\pm 81,2)- \\
-798,4 \\
\end{array}$ & $\begin{array}{c}-22,9(21,0 \pm \\
\pm 1,93)- \\
-19,1\end{array}$ & $\begin{array}{c}1216,0- \\
-(1135,4 \pm \\
\pm 80,5)- \\
-1055,0\end{array}$ & $\begin{array}{c}-28,9(27,0 \pm \\
\pm 1,92)- \\
-25,1\end{array}$ \\
\hline$-0,6--1,0 \sigma$ & $\begin{array}{l}\text { Нижче } \\
\text { середнього }\end{array}$ & $1916,7-1843,5$ & $50,9-52,6$ & $805,3-747,5$ & $19,1-17,8$ & $782,2-717,2$ & $18,7-17,1$ & $1039,0-974,4$ & $24,7-23,2$ \\
\hline$-1,1--2,0 \sigma$ & Низький & $1825,2-1660,5$ & $43,6-39,6$ & $733,0-602,9$ & $17,4-14,3$ & $701,2-554,8$ & $16,6-13,3$ & $958,3-813,4$ & $22,8-19,3$ \\
\hline$<-2,0 \sigma$ & \begin{tabular}{|l} 
Дуже \\
низький
\end{tabular} & $<1660,5$ & $<39,6$ & $<602,9$ & $<14,3$ & $<554,8$ & $<13,3$ & $<813,4$ & $<19,3$ \\
\hline
\end{tabular}

Примітка. $\square$ - середній рівень функціональної підготовленості. 
ності $€$ вищим за «безпечний рівень здоров'я» за критерієм Г. Л. Апанасенка [1]. Порівнюючи зі стандартами для хлопців 11-12 років розробленими Я. П. Пярнатом [8], отримані дані є дещо нижчими.

У літературних джерелах ми не знайшли стандартів оцінки анаеробної продуктивності дівчат та хлопців 11-12 років, тому отримані нами дані порівняти неможливо.

Висновки. Зараз опубліковані стандарти фуннкціональної підготовленості лише для вікових категорій осіб 17-19 і 20-22 років. Авторська методика розробки стандартів функціональної

\section{Література}

1. Апанасенко ГЛ, Попова ЛА, Магльований АВ. Санологія (медичні аспекти валеології) [Sanology (medical aspects of valeology)]: підручник для лікарів-слухачів закладів (факультетів) післядипломної освіти. Львів: Кварт; 2011. 303 с.

2. Брезденюк О. Аеробні можливості студентів 17-21 року з різним компонентним складом маси тіла [Aerobic capacities of students aged 17-21 years with different body mass constitution]. Фізична активність, здоров'я i cnopm. 2014; 1(15): 9-18

3. Дуло ОА, Фурман ЮМ. Порівняльна характеристика аеробної продуктивності дівчат з різним соматотипом, які проживають у гірських та низинних районах Закарпаття [Comparative characteristics of aerobic productivity of girls with different somatotype residing at high altitude and lowland of Transcarpathia]. Biomedical and Biosocial Anthropology. 2013; 20: 23-6.

4. Денисова ЛВ, Хмельницкая ИВ, Харченко ЛА. Измерения и методы математической статистики в физическом воспитании и спорте [Mеаsurements and mathematic statistics methods in physical education and sport]: учеб. пособие для вузов. Киев: Олимп. лит.; 2008. 127 с.

5. Карпман ВЛ. Тестирование в диагностике физической работоспособности и функциональной готовности спортсменов [Testing in diagnosis of physical work capacity and functional fitness of athletes]. Москва: Физкультура и спорт; 1987. 304 с.

6. Купер К. Аэробика для хорошего самочувствия [Aerobics for good wellbeing]. Москва: Физкультура и спорт; 1989. 224 с.

7. Пирогова ЕА, Иващенко ЛЯ, Страпко НП. Влияние физических упражнений на работоспособность и здоровье человека. Киев: Здоровье; 1986. 252 c.

8. Пярнат ЯП. Возрастно-половые стандарты (10-50 лет) аэробной способности человека [Age and gender standards (10-50 years) of human aerobic capacity] [авторефрерат]. Москва, 1983. 44 c.

9. Фурман ЮМ, Зуграва МО, Брезденюк ОЮ, Сулима АС, Нестерова СЮ. Адаптація студентів Подільського регіону 17-21 року до фізичної роботи в аеробному й анаеробному режимах енергозабезпечення. Український журнал медицини, біології та спорту. 2018; Том 3. № 3 (12): 235-42. DOI: $10.26693 / \mathrm{jmbs} 03.03 .235$

10. Фурман Ю, Мірошніченко В, Брезденюк О. Оцінка функціональної підготовленості організму молоді 20-22 років [Assessing functional fit- підготовленості базується на визначенні середнього арифметичного показника, отриманого в результаті обстеження великої кількості осіб однорідного контингенту. Градація стандартів встановлюється у межах діапазону середнього квадратичного відхилення - $\sigma$. Розроблені стандарти охоплюють увесь спектр функціональної підготовленості підлітків 11-12 років.

Перспективи подальших досліджень. Подальші дослідження будуть спрямовані на розробку стандартів оцінки фрункціональної підготовленості осіб інших вікових категорій.

ness of the body of youth aged 20-22 years]. Фізичне виховання, сnорm культура здоров'я у сучасному суспільстві. 2019; 2(46): 41-7. https://doi. org/10.29038/2220-7481-2019-02-41-47

11. Фурман ЮМ, Мірошніченко ВМ, Драчук СП. Перспективні моделі фізкультурно-оздоровчих технологій у фізичному вихованні студентів вищих навчальних закладів [Perspective models of physical culture and health related technologies in physical education of higher education institution students]: монографія. Київ: Олімп. літ.; 2013. 184 с.

12. Cooper K. Running Without Fear. New York, 1985. 125 p.

13. Del Rosso S, Nakamura FY, Boullosa DA. Heart rate recovery after aerobic and anaerobic tests: is there an influence of anaerobic speed reserve? Journal of Sports Sciences. 2017;35(9):820-827. doi:10.1080/02640414 .2016 .1166391

14. Frikha M, Chaari N, Mezghanni N, Souissi N. Influence of warm-up duration and recovery interval prior to exercise on anaerobic performance. $\mathrm{Bi}$ ology of Sport. 2016:33(4):361-66. doi:10.5604/20831862.1221830

15. Furman Y, Brezdeniuk O. Influence of run workloads in a mixed energy supply mode upon functional preparedness of students with a «high» fat component content. Physical education, sports and health in modern society. Lutsk. 2017; 1(37): 52-8. https://doi.org/10.29038/2220-7481-2017-0152-58

16. Furman YuM, Miroshnichenko VM, Brezdeniuk OYu, Furman TYu An estimation of aerobic and anaerobic productivity of an organism of youth aged 17-19 years old of Podilsk region. Pedagogics, psychology, medical-biological problems of physical training and sports. 2018; 22(3):136-41. doi:10.15561/18189172.2018.0304

17. Inbar O, Bar-Or O, Skinner JS. The Wingate anaerobic test: development and application. Champaign, I. L : Human Kinetics, 1996. 110 p.

18. Miroshnichenko VM, Salnykova SV, Brezdeniuk OY, Nesterova SY, Sulyma AS, Onyshchuk VE, Gavrylova NV. The maximum oxygen consumption and body structure component of women at the first period of mature age with a different somatotypes. Pedagogics, psychology, medical-biological problems of physical training and sports. 2018; 22 (6): 306-12. https:// doi. org/10.15561/18189172.2018.0605

19. Shögy A, Cherebetin G. Minutentest auf dem fanradergometer zur bestimmung der anaeroben capazitat. Eur. J. Appl. Physiol. 1974; 33: 171-6.

Надійшла 6.02.2020 